\title{
Quad-Band Dual-Layer Microstrip Antenna Design for Mobile Handset
}

\author{
Gada Mahmood Faisal ${ }^{1}$, Kaydar Majeed Quboa ${ }^{1}$, Dia Mohamad Ali ${ }^{2, *}$ \\ ${ }^{1}$ Elec. \& Com. Dept, College of Engineering, Mosul University, Mosul /Iraq \\ ${ }^{2}$ Com. Dept, College of Electronic Engineering, Mosul University, Mosul /Iraq \\ *Corresponding author: dia_mohamad@yahoo.com
}

Received January 25, 2014; Revised January 30, 2014; Accepted February 09, 2014

\begin{abstract}
Due to the rapid acceleration and evolution of the wireless communication and their equipment, integrating more services in the personal devices, Personal Digital Assistance (PDA) devices has to work in multiband frequencies. In this paper, a quad-band, dual-layer Microstrip Antenna was proposed. The proposed antenna is suggested to be used in a mobile phone handset that covers four frequency bands which include GSM 900 (889-960), GSM 1800 DCS 1800 (1710-1885)W-CDMA (Wideband Code Division Multiple Access); IMT 2000 (International Mobile Telecommunication)1885-2200, Bluetooth and Wi-Fi/WLAN (IEEE $802.11 \mathrm{~b} / \mathrm{g} / \mathrm{n}$ ) ISM 2450 (Industrial, Scientific and Medical) (2400-2500). The antenna is fixed on a printed circuit board together with a standard mobile battery and LCD. All other components were packed in a mobile phone handset plastic cover. An extensive analysis of the return loss, radiation pattern, and gain of the designed antenna with and without cover were presented. Packing effects on the antenna parameters were studied, the proposed antenna shows return loss (RL) of -16 dB at $0.92 \mathrm{GHz} ;-20 \mathrm{~dB}$ RL at $1.735 \mathrm{GHz} ;-37 \mathrm{~dB}$ RL at $2.1 \mathrm{GHz}$; and $-16 \mathrm{~dB}$ RL at $2.42 \mathrm{GHz}$ which are encouraging results. Designing and simulation of the proposed antenna were based on CST software package.
\end{abstract}

Keywords: microstrip antenna, Quad band, mobile, patch

Cite This Article: Gada Mahmood Faisal, Kaydar Majeed Quboa, and Dia Mohamad Ali, "Quad-Band DualLayer Microstrip Antenna Design for Mobile Handset." American Journal of Electrical and Electronic Engineering, vol. 2, no. 2 (2014): 51-56. doi: 10.12691/ajeee-2-2-4.

\section{Introduction}

Microstrip radiators were first proposed as early as 1953 while the first actual microstrip antenna appeared in 1974 [1]. Microstrip patch antennas (MPAs) consist basically of three layers: metallic layer with antenna radiating patch, dielectric substrate and another metallic layer as the ground plane [2]. The light weight, low cost, low profile, planner configuration and easy in fabrication are the main advantages of MPA which enable it to be used with microwave integrated circuits. In spite of these advantages, MPAs suffer from low gain and relatively large size [3,4].

Due to the development in the field of wireless network and mobile communication, many researches started to develop multi-band MPAs to cover the bands of GSM 900, GSM 1800, GSM 1900, UMTS, Bluetooth, WLAN... etc. Singh et al. [5] designed a conventional rectangular MPA with $\Psi$-shaped structure suitable to work in two different frequency bands. Chakraborty et al. [6], designed a single feed compact rectangular MPA for quad-band applications using four L-shaped slot structure along the length of the patch. Barun [7], designed a single feed quad-band compact rectangular MPA with $L$ slot on the edge of the patch with size reduction as compared to a conventional MPA. Veereshappa and Mulgi [8], designed a slotted rectangular MPA for quad-band operation and ominidiretional radiation characteristics. Jayasinghe et al. [9], designed a small multi-band MPA for GSM 900, GSM 1800, GSM 1900, UMTS, LTE 2300, and Bluetooth applications using a genetic algorithm. Puri and Tiary [10], designed a simple single layer, single feed triangular slot patch antenna with air dielectric substrate for quad-band frequency operation in different wireless applications. Mendha and Kosta [11], designed and simulated a stacked 3-layer rectangular Ultra Wide Band antenna. AL Noman et al. [12], designed a single layer single feed miniaturized MPA for multi services using multi layers separated by dielectric substrates. Kharade and Patil [13], enhanced the gain of the MPA using multi-layer and multi-dielectric layers separated from patch by air as another dielectric. Sayidmarie et al. [14], designed a compact dual-band; dual ring printed monopole antenna for WLAN applications. Wang et al. [15], designed two broad bands MPA using planer line feed to enhance band width by $25 \%$. AL Mously [16], designed a triple-band; multi-layer patch antenna for $0.9,1.8$ and $2.4 \mathrm{GHz}$ frequency bands.

\section{Design Methodolgy}

Different methods can be used in the design of multiband Microstrip antennas. These include single short pin loaded between ground plane and patch, slot-loaded on 
patch, stacked multi-resonator rectangular patches on thick substrate. Other types such as single feed dual-band using higher order modes of the circular microstrip antenna (CMSA) and triangular microstrip antenna (TMSA) are out of our scope.

In this paper, three of those methods were hybridized to design a quad-band multi-layer Microstrip antenna. The first step is to design a single layer conventional MPA using single feeder. The second step is to stack a parasitic patch on the top of the active patch separated by different dielectric substrate which will increase the required bandwidth. The third step is to add a single short pin at a suitable distance from the center of the patch to add the higher frequency bands with the aid of shifting feeding point. The required quad-band is:

- 1 st-band centered at fr1 $=0.92 \mathrm{GHz}$.

- 2nd-band centered at fr2 = $1.73 \mathrm{GHz}$.

- 3rd-band centered at fr3 = 2.10 GHz.

- 4th-band centered at $\mathrm{f}_{\mathrm{r} 4}=2.42 \mathrm{GHz}$.

\section{Step 1: Patch Antenna Design}

The antenna design starts with a conventional microstrip antenna MPA1 as shown in Figure 1.

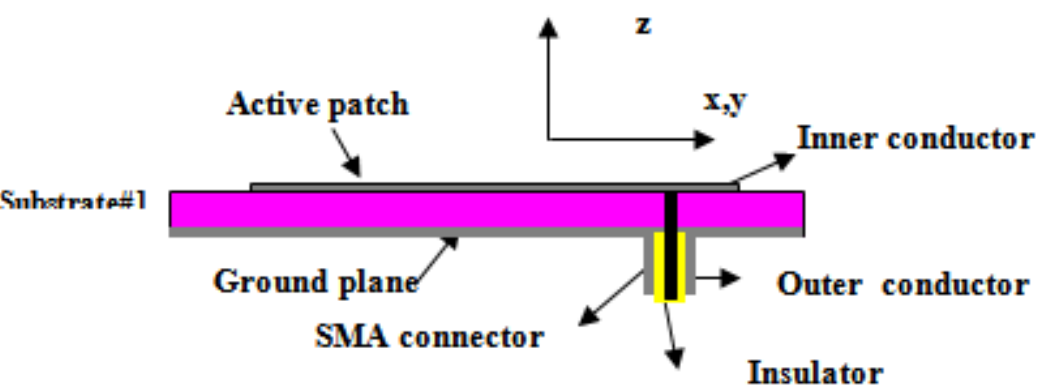

(a)

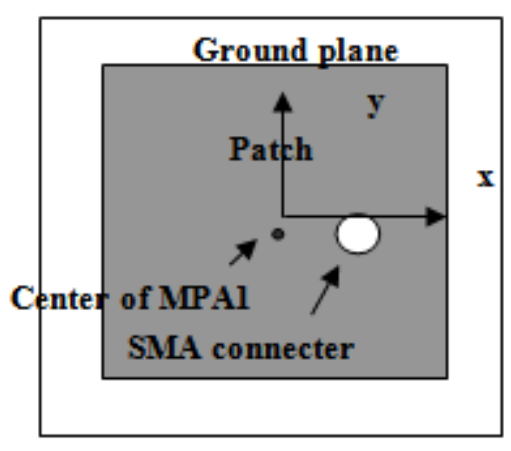

(b)

Figure 1. Conventional MPA1 (a)-Side view, (b)-xy cross section

The basic form of a MPA which consists of active radiating patch on one side of a dielectric substrate and a ground plane on the other side the coaxial feed technique is chosen because the feed can be placed at the desired location inside the patch to match its impedance.

The well-known equations used in calculating dimension of this step are listed in Table 1.

Table 1. Used MPA1 design equations

\begin{tabular}{|c|c|c|}
\hline Parameter & Symbol & Equation used \\
\hline Resonance frequency [17] & $f_{r}$ & $f_{r}=\frac{c}{2 W \sqrt{\left(\varepsilon_{r 1}+1\right) / 2}}$ \\
\hline Effective dielectric constant [17] & $\varepsilon_{e}$ & $\varepsilon_{e}=\frac{\varepsilon_{r 1}+1}{2}+\frac{\varepsilon_{r 1}-1}{2}\left[1+12 \frac{h_{1}}{W}\right]^{-1 / 2}$ \\
\hline Effective Length [17] & $L_{e f f}(m m)$ & $L_{e f f}=\frac{c}{2 f_{r} \sqrt{\varepsilon_{e}}}$ \\
\hline Length of patch [17] & $L(m m)$ & $\begin{array}{c}L=L_{e f f}-2 h \\
* 0.412\left[\frac{\left(\varepsilon_{e}+0.3\right)}{\left(\varepsilon_{e}-0.258\right)} \frac{\left(\frac{W}{h_{1}}+0.26 h_{1}\right.}{\left(\frac{W}{h_{1}}+0.8\right)}\right.\end{array}$ \\
\hline Length of ground plane [17] & $L_{g}(m m)$ & $L_{g}=6 h+L$ \\
\hline Width of ground plane [17] & $W_{g}(m m)$ & $W_{g}=6 h+W$ \\
\hline \multirow[t]{2}{*}{ Inset feed location [18] } & $x_{f}(m m)$ & $x_{f}=\frac{L}{2 \sqrt{\varepsilon_{e}}}$ \\
\hline & $y_{f}(m m)$ & $y_{f}=\frac{W}{2}$ \\
\hline
\end{tabular}

where c is the speed of the light, $W \& L$ are width and length of patch and $\varepsilon_{r}$ is the relative dielectric constant of the substrate.
The antenna is fed with a coaxial connecter modeled as a standard SMA connector with the following specifications [19]: 
- Radius of inner conductor $=0.62 \mathrm{~mm}$.

- Radius of insulator $=2.3 \mathrm{~mm}$.

- Radius of outer conductor $=2.64 \mathrm{~mm}$.

- $\varepsilon_{r}$ of insulator (Teflon-lossy) $=2.1$.

- Length underground plane $=2.1 \mathrm{~mm}$.

Step 2: Adding a Parasitic Patch
Adding the parasitic patch will increase the bandwidth of the MPA1 antenna with more than $15 \%$.

Step 3: Adding the Shorting Pin and Shifting the Feeding Point

Adding the short pin to MPA1 and shifting the feeding point to a proper location will lead to the proposed quadband MPA shown in Figure 2 with specifications and dimensions as given in Table 2.

Table 2. The proposed MPA specifications

\begin{tabular}{|c|c|c|c|c|c|c|c|c|c|c|c|c|c|c|c|c|c|c|}
\hline Parameter & $W_{1}$ & $L_{1}$ & $h_{1}$ & $\varepsilon_{r 1}$ & $W_{2}$ & $L_{2}$ & $h_{2}$ & $\varepsilon_{r 2}$ & $W_{g}$ & $L_{g}$ & $x_{f}$ & $y_{f}$ & $x_{s}$ & $y_{s}$ \\
\hline Value & 34 & 32 & 1 & 4.4 & 56 & 47 & 1.6 & 1.4 & 60 & 50 & 8 & -9 & 7.6 & 0 \\
\hline
\end{tabular}

where:

$W_{1}, L_{1}$, and $h_{1}$ are the active patch dimension in mm;

$W_{2}, L_{2}$, and $h_{2}$ are the parasitic patch dimension in mm; $\varepsilon_{r 1}$ is the relative dielectric constant of the substrate \#1; $\varepsilon_{r 2}$ is the relative dielectric constant of the substrate \#2; $\left(x_{s}, y_{s}\right)$ is the coordination of the added short pin in $\mathrm{mm}$.

The overall antenna structure is shown in Figure 2. The shorting pin locates at $(7.6,0) \mathrm{mm}$ and the feeder at $(8,-9)$ $\mathrm{mm}$.

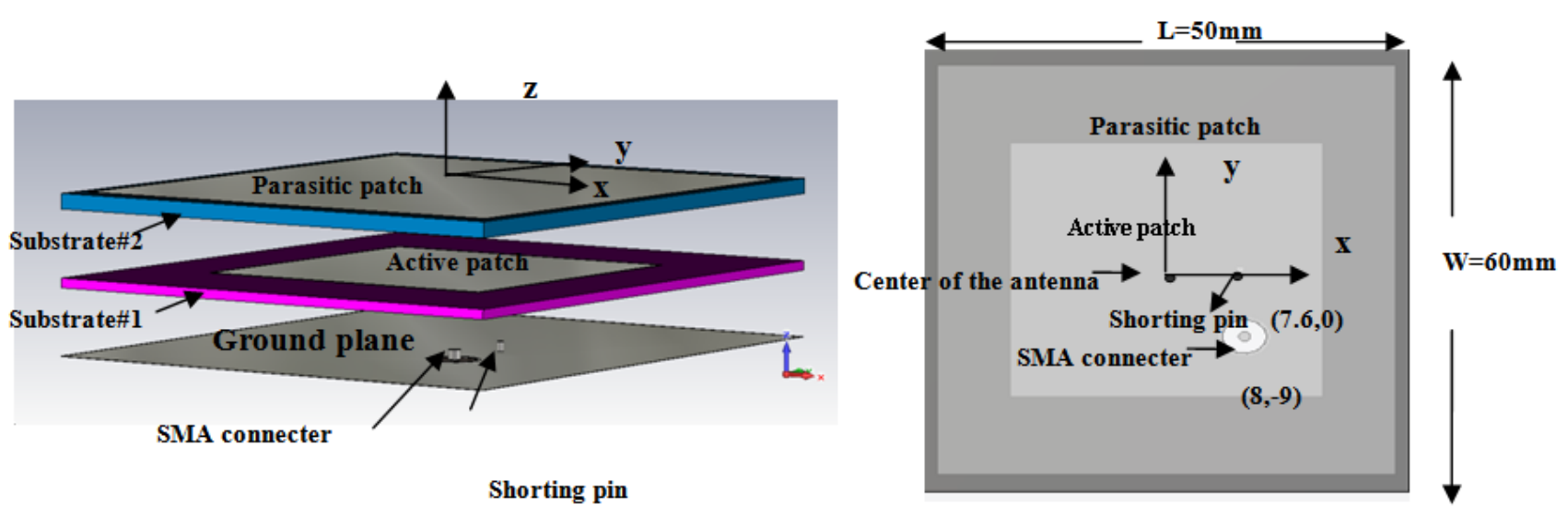

(a)

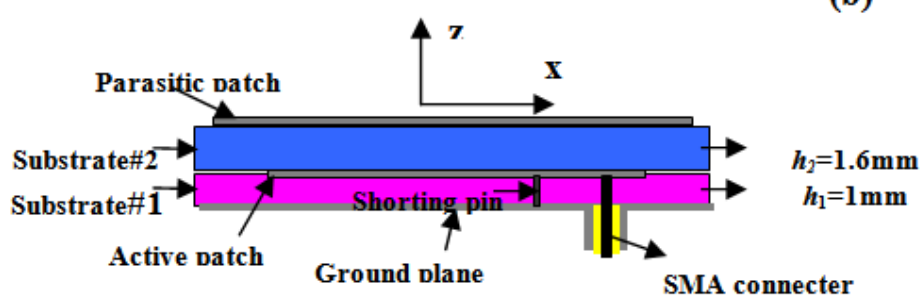

(c)

Figure 2. MPA antenna structure: (a) - Layers details, (b) - Top view, and (c) - Connector details

\section{Simulation Results}

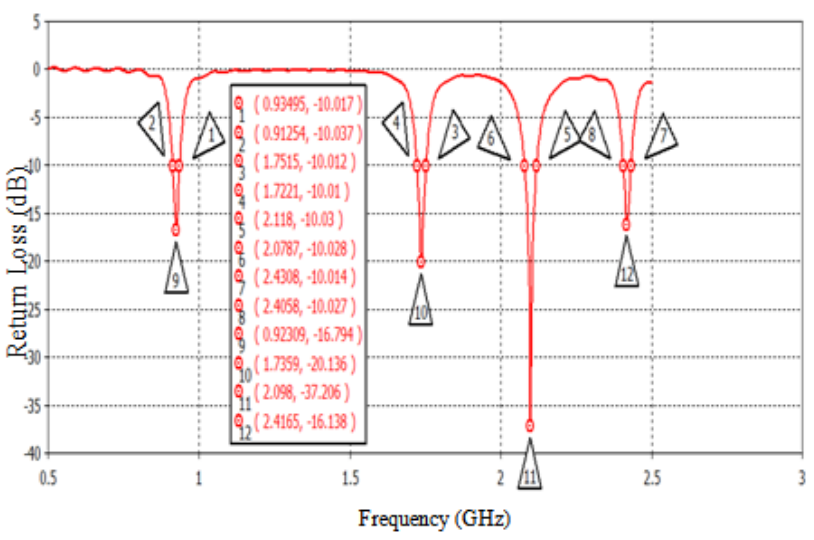

Figure 3. Simulated return loss of quad-band MPA
The proposed quad-band MPA shown in Figure 2 was simulated using CST software package [20]. The detailed return loss (RL) of the final quad-band MPA is shown in Figure 3.

The percent bandwidth $(B w)$ is calculated using the following equation [21]:

$$
B w=\frac{f_{h}-f_{l}}{f_{c}} \times 100 \%
$$

Table 3. Results of the proposed quad-band MPA

\begin{tabular}{|c|c|c|c|c|}
\hline Band & $f_{c}(\mathrm{GHz})$ & RL $(\mathrm{dB})$ & Bandwidth & VSWR \\
\hline$f_{r 1}$ & 0.92 & -16.79 & 2.43 & 1.4 \\
\hline$f_{r 2}$ & 1.735 & -20 & 1.7 & 1.3 \\
\hline$f_{r 3}$ & 2.098 & -37 & 1.87 & 1.05 \\
\hline$f_{r 4}$ & 2.416 & -16 & 1.035 & 1.4 \\
\hline & & & & \\
\hline
\end{tabular}

Where $f_{h}$ and $f_{l}$ are the upper and lower cutoff frequencies of the band respectively at a reference return loss of -10 $\mathrm{dB}$ and $f_{c}$ is the center frequency of the assigned band. The $\mathrm{RL}$, bandwidth and voltage standing wave ratio (VSWR) 
of each band with its center frequency (resonance frequency) are given in Table 3.

The input impedance of the proposed quad-band MPA is investigated as a function of frequency for both real and imaginary parts of antenna's impedance as shown in Figure 4.
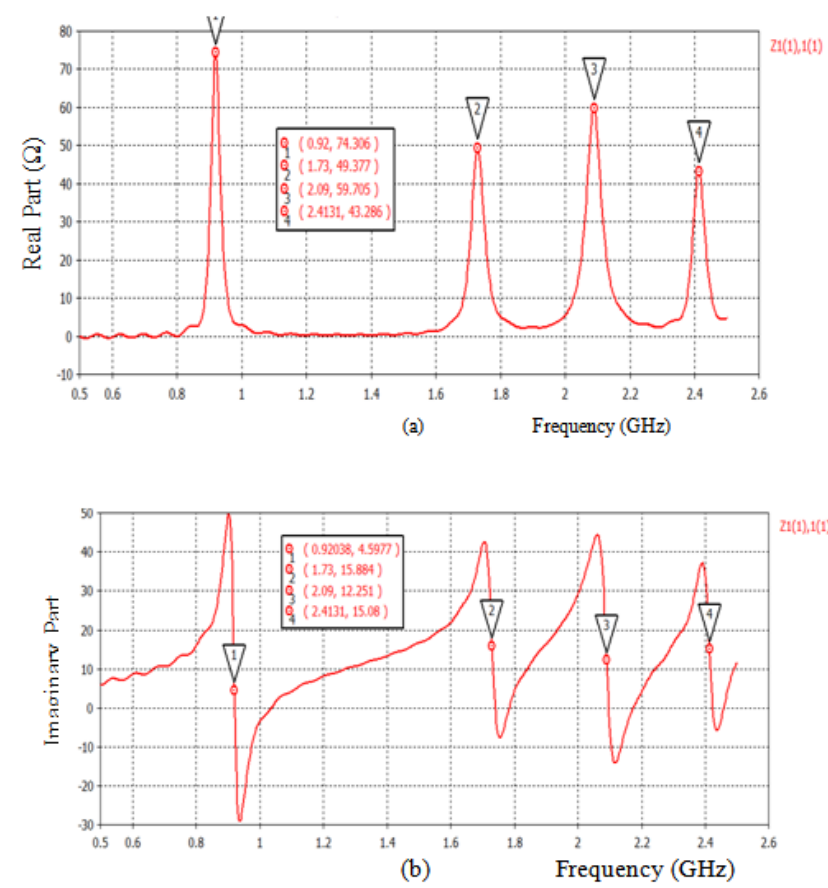

Figure 4. (a) Real part of MPA impedance, (b) Imaginary part of MPA impedance

The input impedance at the resonance frequencies which satisfied the VSWR condition are given in Table 4 .

Table 4. Quad-band MPA impedance

\begin{tabular}{|c|c|}
\hline Frequency $(\mathrm{GHz})$ & Impedance $(\Omega)$ \\
\hline$f_{r 1}=0.92$ & $74.3+\mathrm{j} 4.6$ \\
\hline$f_{r 2}=1.735$ & $49.4+\mathrm{j} 15.9$ \\
\hline$f_{r 3}=2.098$ & $59.7+\mathrm{j} 12.3$ \\
\hline$f_{r 4}=2.42$ & $43.3+\mathrm{j} 15.1$ \\
\hline
\end{tabular}

Table 4 meets the results obtained from drawing the input impedance using Smith chart. As shown in Figure 5, the normalized input impedance approaches the unity (matching point) at four different frequencies. It is clear that these frequencies matched with the VSWR values in Table 3.

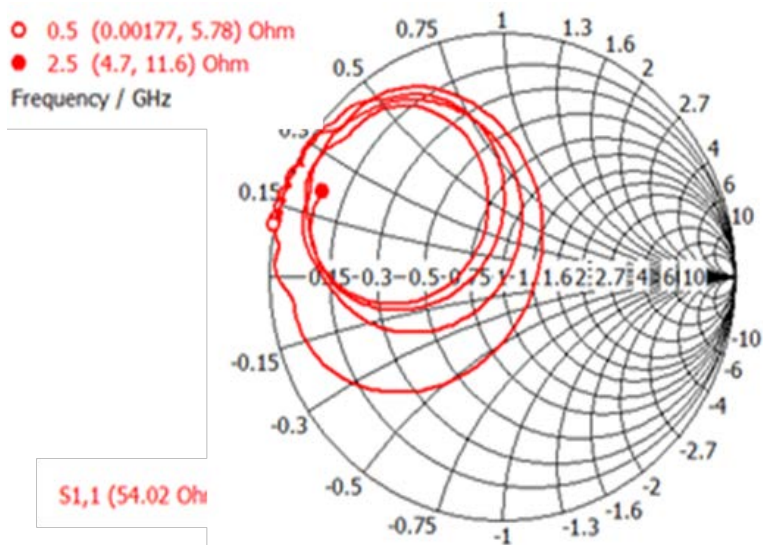

Figure 5. Smith chart for MPA antenna

\section{Antenna Packing}

The designed quad-band MPA antenna has been assembled on printed circuit board (PCB), with a standard mobile battery, LCD monitor and all are placed in a plastic cover with air gap surrounding all components as shown in Figure 6.

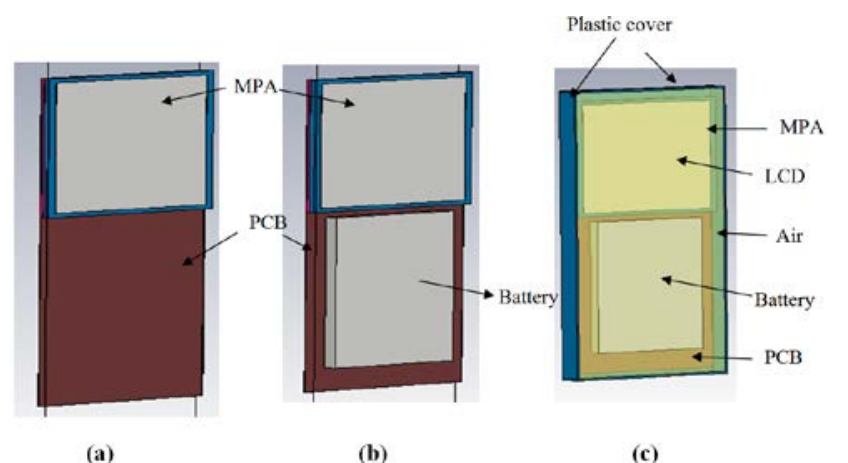

Figure 6. (a) MPA on PCB, (b) MPA on PCB and battery, (c) PCB on PCB battery, LCD monitor and cover

The physical dimensions of PCB, battery, LCD monitor $\&$ plastic cover are chosen to be as those of Samsung Galaxy 2 mobile handset as given in Table 5.

Table 5. Handset specifications

Table 5. Handset specifications
\begin{tabular}{|c|c|c|c|}
\hline $\begin{array}{c}\text { Printed circuit } \\
\text { board }\end{array}$ & Material & Dimensions & $\varepsilon_{r}$ \\
\hline Battery & PEC & $(120 \times 60 \times 0.2) \mathrm{mm}$ & 4.9 \\
\hline Cover & plastic & $\begin{array}{c}(125 \times 65 \times 8.1) \& 0.8 \mathrm{~mm} \\
\text { thickness }\end{array}$ & 2.5 \\
\hline Monitor & LCD & $(125 \times 65 \times 0.8) \mathrm{mm}$ & 4.78 \\
\hline Surrounding Space & Air & & 1 \\
\hline
\end{tabular}

In order to evaluate the effect of the packing process, the packed mobile handset has been simulated using CST simulation software and the RL is investigated. The assembled components caused the resonance frequencies to be shifted as given in Table 6. It is clear from Table 6 that small changes in resonance frequencies (1.735 changed to 1.731 and $2.41 \mathrm{GHz}$ changed to $2.42 \mathrm{GHz}$ ) occurred.

Table 6. The quad-band MPA with cover

\begin{tabular}{|c|c|c|c|c|}
\hline Frequency $(\mathrm{GHz})$ & $f_{r 1}=0.92$ & $f_{r 2}=1.731$ & $f_{r 3}=2.098$ & $f_{r 4}=2.41$ \\
\hline RL & -16 & -25 & -34 & -21 \\
\hline
\end{tabular}

It is worth noting that MPA is covered with a dielectric layer to protect it from the environment, or painted with dielectric paint. This dielectric layer may influence the characteristics of the antenna and cause a shift in resonance frequencies.

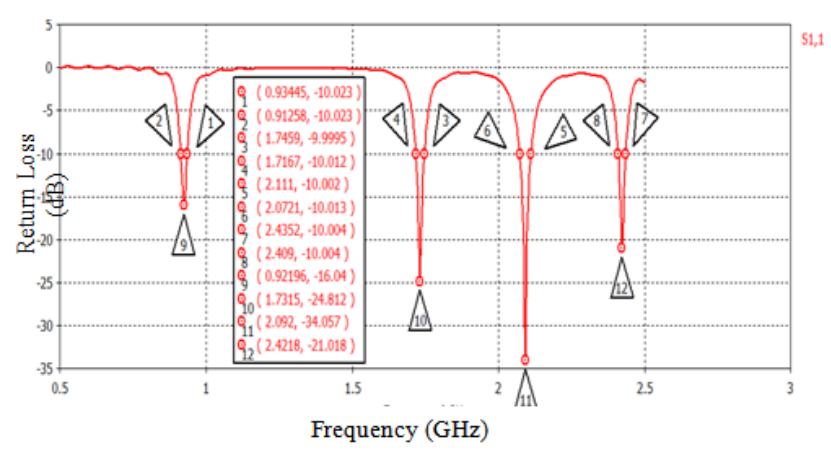

Figure 7. Return loss of quad-band MPA with cover 
The return loss of the assembled quad-band MPA antenna with cover shown in Figure 6 is simulated and the result is shown in Figure 7.

The radiation patterns for $\mathrm{E}$ and $\mathrm{H}$-plane of the proposed antenna with cover at frequencies $0.92 \mathrm{GHz}$, 1.731 GHz, 2.09 GHz and 2.41 GHz are shown at Figure 8.

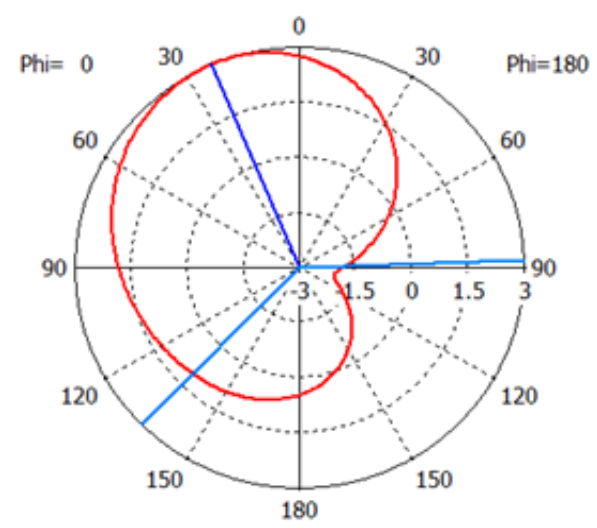

E-plane phi $=0$

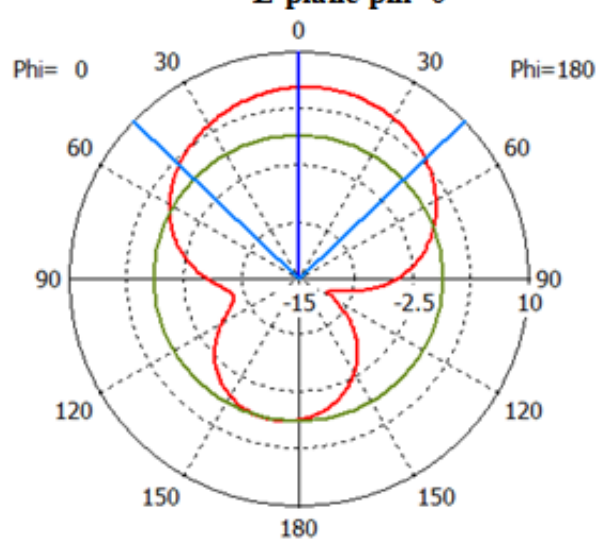

E-plane phi $=0$

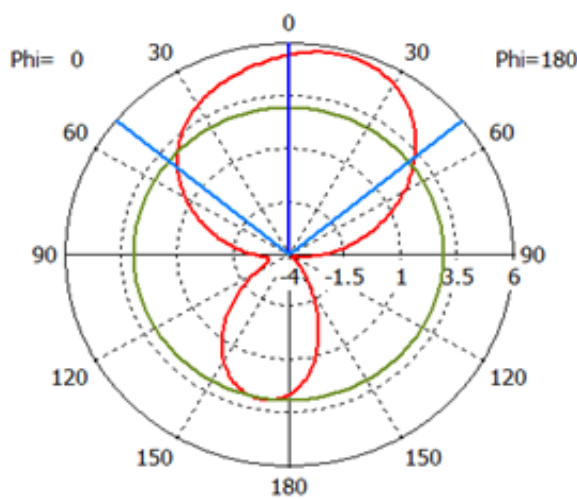

E-plane phi $=0$

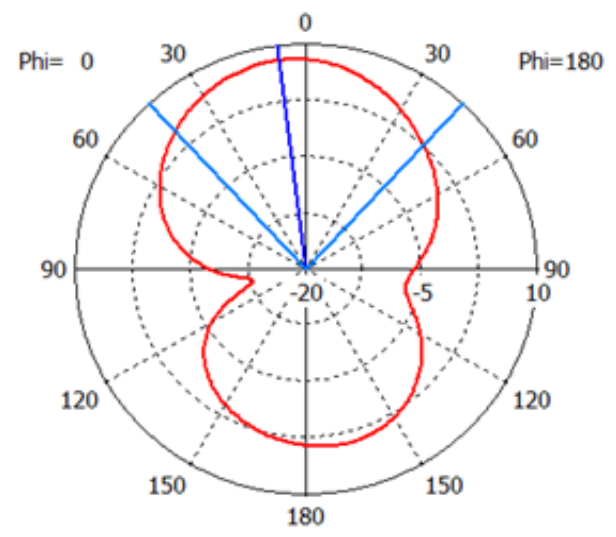

E-plane phi $=0$
In CST software, the mode is chosen to be multi-mode operation which will help in choosing the proper mode for each operating frequency [22]. The radiation pattern of the proposed MPA with cover is shown in Figure 8.a in the mode TM13 at frequency of $0.92 \mathrm{GHz}$ and in the mode TM11 for other frequencies.

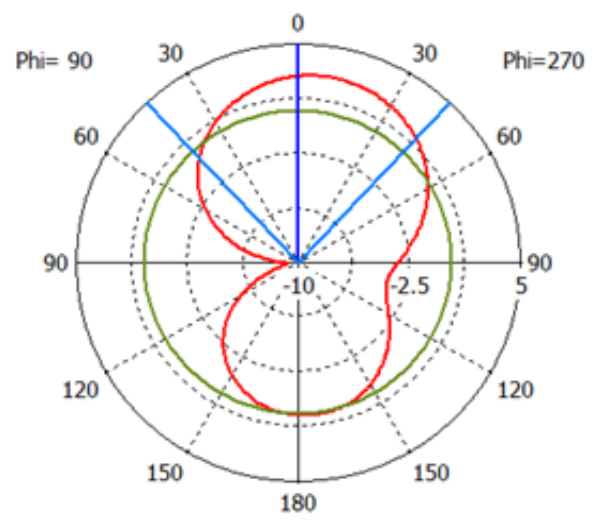

(a)

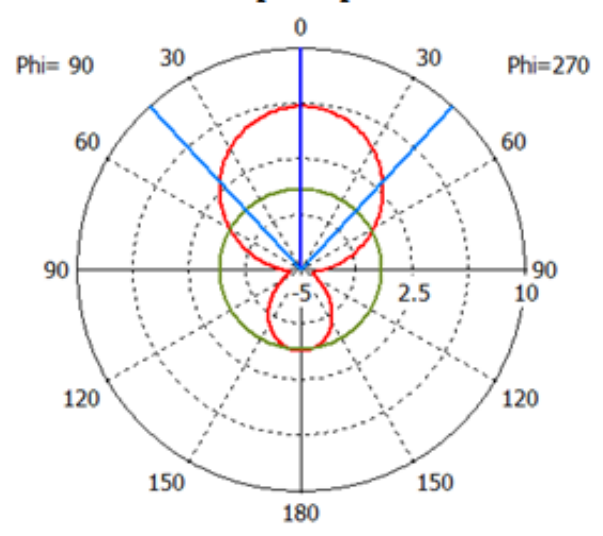

H-plane phi $=90$

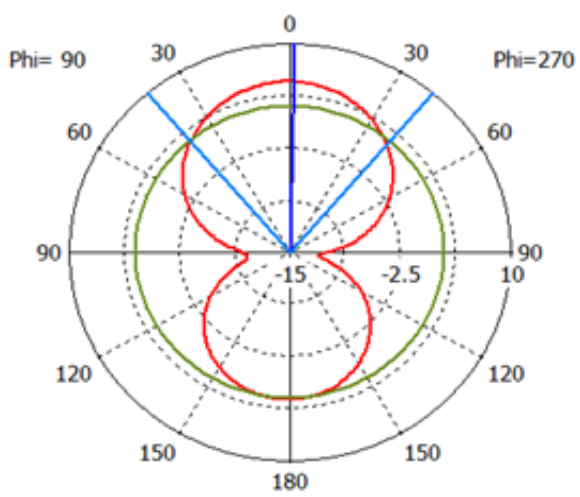

(c)

$$
\text { H-plane phi }=90
$$

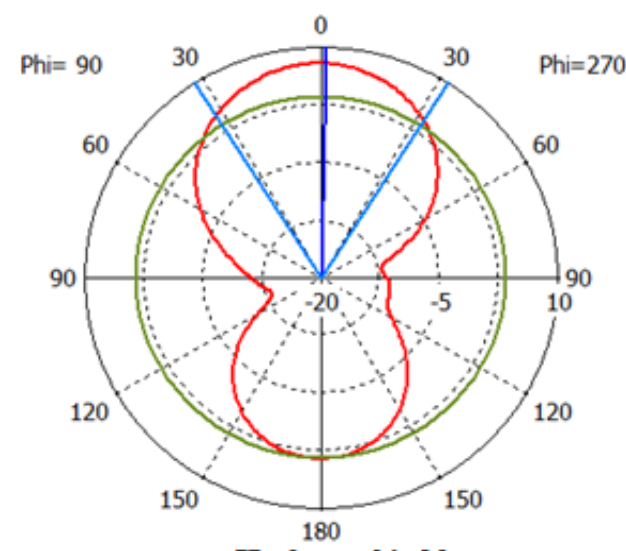

H-plane phi $=90$

Figure 8. The radiation pattern of the proposed MPA with cover at: (a) $0.92 \mathrm{GHz}$, (b) $1.731 \mathrm{GHz}$, (c) $2.098 \mathrm{GHz}$, and (d) $2.41 \mathrm{GHz}$ 
From the radiation pattern figure shown in Figure 8 the directivity for the resonance frequencies of the proposed quad-band MPA antenna with cover is given in Table 7.

Table 7. The directivity of quad-band MPA with cover

\begin{tabular}{|c|c|c|c|c|}
\hline Frequency $(\mathrm{GHz})$ & $f_{r 1}=0.92$ & $f_{r 2}=1.731$ & $f_{r 3}=2.098$ & $f_{r 4}=2.41$ \\
\hline Directivity $(\mathrm{dBi})$ & 3.151 & 6.096 & 5.702 & 7.992 \\
\hline
\end{tabular}

\section{Conclusion}

A single feed dual layer rectangular microstrip antenna with single short pin has been proposed. It is shown that the proposed quad-band antenna can operate effectively in four frequency bands in the frequency ranges of GSM (900 MHz), GSM (1800 MHz), IMT 2000 (885-2200), Bluetooth and Wi-Fi (2400-2500). Four center frequencies are operating at: 920, 1735, 2098 \& $2420 \mathrm{MHz}$. The bandwidth for each frequency was $22.4 \mathrm{MHz}, 29.4 \mathrm{MHz}$, $40 \mathrm{MHz}$, and $25 \mathrm{MHz}$ respectively. Maximum gain of the antenna is found to be about $4.39 \mathrm{dBi}$ at $2.42 \mathrm{GHz}$. The location of the single short pin is optimized in such a way that the antenna can operate in four suitable bands. The antenna with the battery and LCD were fixed together on the printed circuit board and packed in a plastic cover. The dimensions of the designed antenna were $50 \times 60 \times 2.775$ mm.

The proposed antenna characteristics such as return loos, radiation pattern and working bandwidth were acceptable. It is expected that the proposed MPA will be very useful for the future mobile systems and suitable for mobiles having a multi services such as Bluetooth, WIFI WIMAX and of course GSM or 3G services all together.

\section{References}

[1] G. Kumar, and K.P. Ray, "Broadband Microstrip Antennas", Artech House, Inc. Boston, London, 2003.

[2] C. A., Balanis, "Modern Antenna Handbook", 1st Edition, John iley \& Sons, Inc., 2008.

[3] J. Y. Jan, and L.C. Tseng, "Small Planar Monopole Antenna with a Shoted Parasitic Inverted-L Wire for Wireless Communications in the 2.4, 5.2 and $5.8 \mathrm{GHz}$ Bands”, IEEE Trans. Antennas and Propag. Vol. 52, NO. 7, Joly 2004, pp-1903-1905.

[4] U. Chakaraborty, S. Chatterjee, S. K. Chowdhury, and P. P. sarkar, "A Compact Microstrip Patch Antenna for Wireless Communication,” Progress In Electromagnetics Research C, Vol. 18, 211-220, 2011.

[5] D. Singh, A. K. Gupta, R. K. Prasad, "Design and Analysis of Dual-Band $\Psi$-Shape Microstrip Patch Pntenna”, International Journal of Advances Engineering \& Technology, Mar. 2013. Conference IJAET.
[6] U. Chakaraborty, B. Mazumdar, S.K. Chowdhury, A.K.Bhattacharjee, "A Compact L-slot Microstrip Antenna for Quad band Applications in Wireless Communication”, Global Journal of Researches in Engineering Electrical and Electronics Engineering ,vol 12, Issue 2, Version 1.0, Feb. 2012.

[7] B. Mazumdar, "Design Of L-Slit Microstrip Patch Antenna For Wimax \& Hiperlan Applications", Journal of computer Networking, Wierless and Mobile Communications (JCNWMC), vol. 2 Issue 1, Sep-2012, 45-50. Conference TJPRC Pvt. Ltd.

[8] M. Veereshappa and S. N. Mulgi, "Design and Development of Quad Band Rectangular Microstrip Antenna with Ominidireciona Radiation Characteristics", / International Journal Of Coputational Engineering Research.

[9] J. W. Jayasinghel, J. Anguera, and D. N. Uduwawala, "A Simple Design of Multiband Microstrip Patch Antenna Robust to Fabrication-Tol-Erancea for GSM ,UMTS, and Bluetooth Applications by Using Genetic Algorithm Optimization”, Progress In Electro-magnetics Research M, Vol. 27, 255, 269, 2012.

[10] S. C. Puri, and M.G. Tiary, "A Novel Quad Band Rectangular Microstrip Patch Antenna for Wieless Applications”, IJCA Proceedings on International Symposium on Devices MEMS, Intelligent System \& Communication, 24-26-2011.

[11] S. E. Mendhe, and Y P. Kosta, "Stacked Three Layer Rectangular Microstrip Patch Antenna for Ultra Wide Band Applications", International journal of Computer Science and Communication, vol. 3, No, 1, January-June 2012, pp. 145-147.

[12] A. AL Nomanovi, M. R. Chowdhury, R. A. Zuboraj and A. Matin, "Design of Miniaturized Dual Band Microstrip Antenna Loaded with Asymmetric J slot”, Technol 2012, 2: 1.

[13] A. R. Kharade, V. P. Patil, "Enhancement of Gain of Rectangular Micro strip Antenna Using Multi layer Multi dielectric structure", IOSR Journal of Electronics and Communication Engineering (IOSRJECE) vol. 2, Issue 6 (Sep-Oct 2012), PP 35-40, www.io srjournals.org.

[14] K.H. Sayidmarie and T.A. Nagem, "Compact Dual-Band DualRing Printed Monopole Antennas For WLAN Applications", Progress In Electromagnetic Research B, Vol. 43, 313-331, 2012.

[15] H.H. Wang, K., Yang, Z.Y. Lei and C. I. Li, "Broadband Microstrip Antennas using Coplanar Feed line”, Progress In Electromagnetics Research Letters, Vol. 20, 129-136, 2011.

[16] S.I. Al-Mously, "Design and Performance Enhancement of Cellular Handset Antennas and Assessment of Their EM Interaction with a Human", PhD Thesis, Academy of Graduate Studies, School of Applied Science and Engineering Dept. of Electrical and Computer Eng. Libya. Aug., 2009.

[17] C. A. Balanis, "Antenna Theory, Antenna and design", John Wiley \& Sons Inc., 2nd Edition, 2005.

[18] G. Frank, "High Frequency Technology: Principles of Mobile Communication Technology”, Rectangular Patch Antenna Design Using Coaxial Probe Peed. Htm.

[19] K. Parikh, "Simulation of Rectangular, Single Layer, Coax-Fed Patch Antennas Using Agilent High Frequency Structure Simulator (HFSS)", MSc. Thesis, Faculty of the Virginia Polytechnic. Institute and State University. December 2003.

[20] Computer Simulation Technology: http://www.cst.com/.

[21] L. Warren, and A. Gary, "Antenna Theory and Design” 2nd. Edition, New York, ISBN 0-471-02590-9, 1998.

[22] CST Studio Suite under "Help - > Support Account Settings...”. Waveguide Port Overview [CST MWS]. 